\title{
BMJ Open Can HIV reverse transcriptase activity assay be a low-cost alternative for viral load monitoring in resource-limited settings?
}

\author{
Soham Gupta, ${ }^{1}$ Riya Palchaudhuri, ${ }^{1}$ Ujjwal Neogi, ${ }^{2}$ Hiresave Srinivasa, ${ }^{1}$ \\ Per Ashorn, ${ }^{3}$ Ayesha De Costa, ${ }^{4}$ Clas Källander, ${ }^{5}$ Anita Shet ${ }^{6}$
}

To cite: Gupta S,

Palchaudhuri R, Neogi U, et al. Can HIV reverse transcriptase activity assay be a low-cost alternative for viral load monitoring in resourcelimited settings?. BMJ Open 2016;6:e008795.

doi:10.1136/bmjopen-2015008795

- Prepublication history for this paper is available online. To view these files please visit the journal online (http://dx.doi.org/10.1136/ bmjopen-2015-008795).

SG and UN are cocorresponding authors.

Received 28 May 2015 Revised 16 November 2015 Accepted 27 November 2015

CrossMark

For numbered affiliations see end of article.

Correspondence to

Soham Gupta;

soham.gupta@ki.se and

Ujjwal Neogi; ujjwal.neogi@ ki.se

\section{ABSTRACT}

Objective: To evaluate the performance and cost of an HIV reverse transcriptase-enzyme activity (HIV-RT) assay in comparison to an HIV-1 RNA assay for routine viral load monitoring in resource limited settings.

Design: A cohort-based longitudinal study.

Setting: Two antiretroviral therapy (ART) centres in Karnataka state, South India, providing treatment under the Indian AIDS control programme.

Participants: A cohort of 327 HIV-1-infected Indian adult patients initiating first-line ART.

Outcome measures: Performance and cost of an HIV-RT assay (ExaVir Load V3) in comparison to a gold standard HIV-1 RNA assay (Abbott m2000rt) in a cohort of 327 Indian patients before (WK00) and 4 weeks (WK04) after initiation of first-line therapy.

Results: Plasma viral load was determined by an HIV1 RNA assay and an HIV-RT assay in 629 samples (302 paired samples and 25 single time point samples at WK00) obtained from 327 patients. Overall, a strong correlation of $r=0.96$ was observed, with good correlation at WK00 ( $r=0.84)$ and at WK04 ( $r=0.77)$. Bland-Altman analysis of all samples showed a good level of agreement with a mean difference (bias) of $0.22 \log _{10}$ copies $/ \mathrm{mL}$. The performance of ExaVir Load V3 was not negatively affected by a nevirapine/efavirenz based antiretroviral regimen. The per test cost of measuring plasma viral load by the Abbott m2000rt and ExaVir Load V3 assays in a basic lab setting was $\$ 36.4$ and $\$ 16.8$, respectively.

Conclusions: The strong correlation between the HIVRT and HIV-1 RNA assays suggests that the HIV-RT assay can be an affordable alternative option for monitoring patients on antiretroviral therapy in resource-limited settings.

Trial registration number: ISRCTN79261738.

\section{INTRODUCTION}

The principal aim of antiretroviral therapy (ART) is durable suppression of replicating plasma virus to undetectable levels, thereby delaying disease progression and prolonging

\section{Strengths and limitations of this study}

- To the best of our knowledge, the current study is the most thoroughly evaluated study of ExaVir Load V3 HIV reverse transcriptase-enzyme activity (HIV-RT assay) from India to date.

- This study was performed in a large number of patients in a longitudinal manner looking into the effects of the non-nucleoside reverse transcriptase inhibitors-based therapy and drug resistance mutations on the performance of the HIV RT-enzyme activity assay.

- Though the assay has been validated before in other non-C subtype settings, in this study the HIV-RT assay was validated on a larger scale in a subtype $C$ predominant setting and subtype $C$ is the most predominant subtype globally, more so affecting the resource-limited settings.

- This study was limited to patients hailing from Southern India and a performance evaluation and cost-effectiveness of the HIV-RT assay needs to be accessed on a national level.

survival. $^{1}{ }^{2}$ Expanding access to ART in resource-limited settings along with close monitoring is needed for successful treatment outcomes. In high income settings, this is achieved by performing quantitative viral load monitoring every 3-6 months, ${ }^{3}$ as viral load monitoring detects early treatment failure. However, in resource-limited settings, therapeutic outcome is evaluated either on the basis of a CD4 $\mathrm{T}$ cell count or clinical findings, ${ }^{4}$ neither of which accurately predicts viral suppression. ${ }^{5}$ Early detection of viral failure by monitoring the viral load also provides the opportunity to intensify adherence counselling to improve adherence to ART, potentially leading to resuppression of viral load before the evolution of drug-resistant virus can take place. ${ }^{6}$

The currently used viral load assays are based on the amplification of HIV-1 virion 
RNA, which is considered impractical for wide-scale use in resource-limited settings, as it requires infrastructure, facilities for molecular diagnostics, expensive equipment and skilled technicians, which are often unavailable. ${ }^{7}$ Simpler, less expensive viral load assays would be very useful in the resource-limited environments that are most impacted by this epidemic.

An alternative to measure the HIV-1 RNA is to measure the activity of the viral reverse transcriptase (RT) enzyme. The ExaVir Load assay (Cavidi, AB, Sweden), a low-cost and technically less demanding assay using an ELISA-based method to measure RT enzyme activity, has shown promising results. ${ }^{8-19}$ Although previous versions of the test have been evaluated against several PCR-based HIV tests that measure viral RNA, there are few comparative studies between ExaVir Load V3 and such molecular real-time assays. ${ }^{14} 1618$ The most recent V3 of the ExaVir Load assay has an enhanced sensitivity (lower detection limit 200 copies $/ \mathrm{mL}$ ) and reduced turnaround time compared to V2. ${ }^{14} 18$

HIV-1 subtype C (HIV-1C) is the dominant strain in most low and middle income countries like India, South Africa and Ethiopia, ${ }^{20}$ and the need for a simple low cost viral load monitoring tool is a priority in these settings. Data available from countries dominated by the HIV-1C epidemic are limited. Where available, evaluations have been mainly performed with earlier version assays (ExaVir Load V1 and V2), which had lower detection limits of 400 copies/mL. ${ }^{711} 21{ }^{22}$ Studies evaluating Exavir Load V3 have been mainly performed in non-C dominated countries. ${ }^{14} 161819$

Thus, we aimed to evaluate the performance of the HIV RT-enzyme activity (HIV RT) assay (ExaVir Load V3) in comparison to a 'gold standard' HIV RNA load (Abbott m2000rt real-time PCR) assay in a cohort of patients before and after initiation of first-line ART in Indian settings. We also compared viral load measurements from both assays in a subset of patients with drug-resistant mutations at baseline. Further, we studied the difference in costs of the two viral load assays in the context of our laboratory setting from a provider perspective.

\section{MATERIALS AND METHODS}

\section{Study participants and samples}

Between April 2010 and September 2011, EDTA plasma samples were collected from HIV-1-infected adult patients attending the Infectious Disease Clinic, St. John's Medical College and Hospital, Bangalore (main site) and ART centre, Krishna Rajendra Hospital, Mysore (peripheral site) enrolled in the HIVIND randomised controlled trial (Trial registration: ISRCTN79261738). ${ }^{23}$ All the patients included in the study initiated ART with reverse transcriptase inhibitor (RTI) drugs, that is, two nucleoside reverse transcriptase inhibitors (NRTI), zidovudine (AZT) or stavudine (d4T) with lamivudine (3TC) + one non-nucleoside reverse transcriptase inhibitor (NNRTI), either nevirapine (NVP) or efavirenz (EFV) as per the standard national AIDS programme guidelines. ${ }^{24}$

Plasma samples were collected at two time points; (1) prior to ART initiation (not longer than 3 months prior) and (2) 4 weeks after ART initiation. The plasma samples were separated within $6 \mathrm{~h}$ of EDTA whole blood collection, aliquoted and stored at $-80^{\circ} \mathrm{C}$ in the main site. Plasma samples aliquoted in the peripheral site were stored at $-20^{\circ} \mathrm{C}$ and transported to the main site on dry ice (every 2 weeks) and then stored at $-80^{\circ} \mathrm{C}$ prior to testing.

\section{Ethical statement}

Ethical approvals for the conduct of the trial were obtained from the Institutional Ethical Review Board of St John's Medical College Hospital, Bangalore (IERB 1/ 369/08-92/2008) and Krishna Rajendra Hospital, Mysore (NO/PS/173/2010). All patients participating in the HIVIND study have given their written consent.

\section{Plasma HIV-1 RNA assay}

Plasma HIV-1 RNA load was measured in the patient cohort using the Abbott Real-Time PCR, m2000rt system with a manual RNA extraction procedure on an m2000sp sample preparation system as per the manufacturer's instructions. The assay was performed using an initial volume of $0.2 \mathrm{~mL}$ plasma, which provides limits of quantification between 150 copies/mL (lower limit of detection) and 10000000 copies/mL (upper limit of detection). In every run, a negative control, a low positive control and a high positive control supplied in the Abbott Realtime HIV-1 control kit were included. This measure using Real-Time PCR was considered as the gold standard. This protocol was validated by an external quality control programme by the Quality Control for Molecular Diagnostics, Glasgow, Scotland (QCMD, http://www.qcmd.gov) on a 2010 panel (Consisting of four HIV-1B samples, two HIV-1C samples, one HIV-1A/ G sample and one HIV-1 negative sample) and obtained a highly satisfactory score.

\section{Plasma HIV RT enzyme activity assay}

The viral RT enzyme activity was quantified using Cavidi ExaVir Load V3 as per the instructions of the manufacturer. ${ }^{14}$ In an ELISA-based format, the RT activity of the RT enzyme recovered from $1 \mathrm{~mL}$ of patient plasma was determined and compared to a standard curve based on known amounts of an HIV 1 recombinant RT constructed from the BH10 isolate. The RT activity in the sample was expressed as femtogram HIV-1 RT activity $/ \mathrm{mL}(\mathrm{fg} / \mathrm{mL})$ plasma that was translated into RNA copies/mL equivalent by the ExaVir Load analyser software. The lower detection limit of the assay was $\geq 1 \mathrm{fg} / \mathrm{mL}$ that is, $\geq 200$ copies $/ \mathrm{mL}$. In every run, a single positive control and a negative control were used to monitor the performance of the RT extraction process 
and to access between run variations. The positive control was prepared by pooling the EDTA plasma from a high HIV-1 viral load sample and HIV-1 negative plasma; $1.2 \mathrm{~mL}$ was aliquoted and stored in a $-80^{\circ} \mathrm{C}$ freezer. The laboratory personnel running the ExaVir Load V3 assay were blind to the plasma HIV-1 RNA values.

\section{HIV-1 subtyping and baseline drug resistance}

Genotypic resistance testing (GRT) was performed on the baseline plasma samples. Briefly, the reverse transcriptase (RT) region of the HIV-1 pol gene was amplified and sequenced using the primers described by us previously. ${ }^{25}$ HIV-1 subtyping was determined on the basis of the pol gene as well as the env gene (wherever sequence data were available). ${ }^{26-28}$ using the maximum likelihood (ML) phylogenetic tree based on reference sequences downloaded from the Los Alamos Database (http://www.hiv.lanl.gov). Primary drug resistance analysis was evaluated using the WHO list of mutations from 2009 (WHO_SDRM 2009). ${ }^{29}$

\section{Comparative cost analysis}

We did an analysis comparing the costs between Abbott m2000rt and ExaVir Load V3 from a provider (laboratory service provider) perspective. We used costs from our lab for this purpose. Costs considered included annuitised capital costs for the two different instruments including operator-supplied instruments. These are instruments which are necessary in case of a new laboratory. In case of Abbott, the operator-supplied instruments included single-channel micropipettes, two dry baths and a vortex. For ExaVir Load V3, they included micropipettes (both single-channel and multichannel), an ELISA plate reader, an incubator, a rocker and a vortex.

Costs for start-up kits, human resource costs (including time for training), annual maintenance, reagents and other consumables were also considered. We assumed the working life for Abbott m2000rt and ExaVir Load V3 to be 5 years, and a discount rate of $5 \%$ was applied.

\section{Assumptions}

Number of patients: There are at present 1500 ART-experienced patients in our ART centre. Assuming that viral load monitoring of these patients will require to be performed every 6 months, there will be 3000 samples a year.

Maintenance costs: In the case of Abbott m2000rt the costs for servicing, maintenance of instrument and calibration of laser head. In the case of Abbott m2000rt the annual maintenance cost included the costs for servicing, maintenance of instrument and callibration of laser heads.

Human resource skills and training requirements: From our experience, 1 month was required to train a technician on Abbott m2000rt. One week was required for training on ExaVir load V3. We also considered that the technician handling Abbott m2000rt would require to be more senior and experienced (salary $\$ 300$ per month) compared to the technician working with ExaVir Load V3 (salary \$200 per month).

Time for each method of testing: For Abbott m2000rt, a batch of 24 reactions which comprise 21 samples and 3 controls will involve a total time of $8 \mathrm{~h}$ (from the beginning of RNA extraction up until obtaining results), of which $5 \mathrm{~h}$ involve the technician's time. For Exavir Load V3, the assay is performed in batches of 30 samples. Though the turnaround time is $48 \mathrm{~h}$, it involves $5 \mathrm{~h}$ of actual hands-on time per batch. Costs for time of the technicians were calculated against the salaries mentioned above.

In the cost comparison analysis, we did not consider costs associated with the sample collection, storage and transportation as these are common to both tests.

\section{Statistical analysis}

All statistical analyses were performed after the HIV RT and HIV-1 RNA level values were $\log _{10}$ transformed. For analysis, the lower limit of detection of the HIV RT assay $(\leq 200$ copies $/ \mathrm{mL}$ ) was considered; samples showing $<200$ copies $/ \mathrm{mL}$ by any of the assays were assigned a value of 199 copies/mL. With Exavir Load V3, we achieved a varying upper detection limit ranging from $>360000$ to $>770000$ in different runs. Thus, samples with a viral load of $>360000$ (the lowest range of the upper detection limit obtained for ExaVir Load V3) by any of the assays were assigned a viral load of 360000 copies/mL. The diagnostic agreement between the HIV RT assay and the HIV-1 RNA assay at different viral load cut-offs was determined from the $\kappa$ statistic. Pearson's correlation coefficient ( $r$ ) was calculated to study the correlation between $\log _{10}$ HIV RT activity (copies/mL equivalents) and $\log _{10}$ HIV RNA (copies/mL). However, since this coefficient does not take into account the possibility that one measure may differ consistently from the other, we further assessed the level of agreement using pairwise Bland-Altman plots. This plot compares the measures between the two tests by plotting the difference in the two VL measures against the average of the two measures.

\section{RESULTS}

\section{Sample characteristics}

Plasma viral load was obtained from 629 samples collected from 327 HIV-1-infected adult patients, of which 302 were paired (before ART and 4 weeks after ART initiation). HIV-1C was the predominant subtype observed in $98.1 \%(313 / 319)$ of the patients. Six out of 319 genotyped patients $(1.9 \%)$ showed the presence of non-C subtype strains, namely $\mathrm{BC}$ recombinant (1), BD recombinant (1), A1C recombinant (2) and HIV-1A1 (2). Eleven patients $(3.4 \%)$ showed the presence of single primary drug-resistant mutations, with six samples 
Table 1 Comparison of HIV-1 plasma VL levels measured by the HIV RT and HIV-1 RNA assays by ART status, HIV-1 subtypes and RT-drug resistant mutations

\begin{tabular}{|c|c|c|c|c|}
\hline \multirow[b]{2}{*}{ Sample type } & \multirow[b]{2}{*}{ Number of samples } & \multicolumn{2}{|c|}{$\begin{array}{l}\text { Mean viral load } \pm S D \text { in } \\
\log _{10} \text { copies } / \mathrm{mL}\end{array}$} & \multirow{2}{*}{$\begin{array}{l}\text { Mean } \log _{10} \text { viral load } \\
\text { difference } \pm S D \text { in } \\
\log _{10} \text { copies } / \mathrm{mL}\end{array}$} \\
\hline & & ExaVir Load V3 & Abbott m2000rt & \\
\hline All samples & 629 & $3.98 \pm 1.3$ & $4.19 \pm 1.3$ & $0.22 \pm 0.3$ \\
\hline \multicolumn{5}{|l|}{ ART Status } \\
\hline Naïve (baseline at WKO0) & 327 & $5.07 \pm 0.6$ & $5.33 \pm 0.5$ & $0.25 \pm 0.3$ \\
\hline Experienced (WK04) & 302 & $2.79 \pm 0.5$ & $2.97 \pm 0.6$ & $0.19 \pm 0.4$ \\
\hline \multicolumn{5}{|l|}{ Subtype at WKOO $(n=319)^{*}$} \\
\hline C & 313 & $5.08 \pm 0.6$ & $5.33 \pm 0.4$ & $0.25 \pm 0.3$ \\
\hline Non-C & 6 & $5.05 \pm 0.5$ & $5.3 \pm 0.4$ & $0.25 \pm 0.3$ \\
\hline \multicolumn{5}{|l|}{ DRMs at WKOO $(n=319)^{*}$} \\
\hline Wild type (no DRM) & 308 & $5.07 \pm 0.6$ & $5.32 \pm 0.5$ & $0.25 \pm 0.3$ \\
\hline NRTI mutations & 6 & $5.41 \pm 0.3$ & $5.55 \pm 0.01$ & $0.15 \pm 0.3$ \\
\hline NNRTI mutations & 5 & $5.26 \pm 0.2$ & $5.62 \pm 0.2$ & $0.36+0.2$ \\
\hline
\end{tabular}

*Genotyping performed only in baseline samples.

ART, antiretroviral therapy; DRM, drug-resistant mutations, NNRTI, non-nucleoside reverse transcriptase inhibitors; NRTI, nucleoside reverse transcriptase inhibitors; RT, reverse transcriptase; VL, viral load.

harbouring NRTI-associated drug-resistant mutations (DRMs) and five samples with NNRTI-associated mutations (table 1).

\section{Comparison between HIV RT activity and HIV-1 RNA load assay}

There were 54 samples $(8.5 \%)$ that were quantifiable by the HIV-1 RNA assay but were below the detection limit of the HIV RT assay (table 2). At a lower limit of quantification of 200 copies $/ \mathrm{mL}, 90.7 \%$ of the samples showed a quantifiable virus by the HIV RT assay. The percentage of the samples with a quantifiable viral load by the HIV RT assay increased with higher viral load cut-offs by the HIV-1 RNA assay as shown in table 2. Overall, there was acceptable agreement observed between the HIV RT and HIV-1 RNA assays, with excellent agreement observed at higher values of plasma viral load $\geq 3.0 \log _{10}$ copies $/ \mathrm{mL} \quad(\kappa=0.76)$. Of all the samples, $81.7 \%$ (514/ 629) had viral load values by the HIV RT assay, which differed by $<0.5 \log _{10}$ units from the HIV-1 RNA values, while $99.2 \%(624 / 629)$ of the samples differed by $<1.0$ $\log _{10}$ units.

A strong positive correlation was observed between the plasma viral load values by the HIV RT and HIV-1 RNA assays $(\mathrm{r}=0.96)$ in all the samples. A good correlation was noted in ART-naive samples $(\mathrm{r}=0.84)$ as well as in samples at week 04 of ART ( $r=0.77$; figure 1).

Bland-Altman plots for all the samples showed good levels of agreement with a mean difference (bias) of $0.22 \log _{10}$ copies $/ \mathrm{mL}$, with acceptable limits of agreement $\left(-0.45\right.$ and $+0.89 \log _{10}$ copies $\left./ \mathrm{mL}\right)$. A good level of agreement was also observed separately at baseline (mean difference bias of 0.25; range of acceptable limit of agreement: -0.39 and $+0.89 \log _{10}$ copies $/ \mathrm{mL}$ ) and at WK04 (mean difference bias of 0.19; range of acceptable limit of agreement: -0.52 and $+0.89 \log _{10}$ copies $/ \mathrm{mL}$; figure 2).

\section{Influence of current ART and drug-resistant mutations on RT-enzyme activity}

Table 1 shows that the mean $\log _{10}$ difference between the HIV RT and HIV-1 RNA assays both before and after initiation of ART was not significantly different $(<0.25$ $\log _{10}$ copies $/ \mathrm{mL}$ ) but was well within the clinically accepted limit of $0.5 \log _{10}$ copies $/ \mathrm{mL}$. Thus, the performance of the HIV RT assay is not affected by the presence of the NNRTI (nevirapine/efavirenz)-based ART regimen. Also, the presence of either NRTI-associated DRMs (n=6; M41L: 1, D67N: 1, T69D: 1, M184I: 1 and T215S: 2) and NNRTI-associated DRMs ( $\mathrm{n}=5$; Y181C: 1 , K101E: 1 and K103N: 2) showed an acceptable change

Table 2 Agreement between the HIV RT assay and HIV-1 RNA assay at different PVL levels

\begin{tabular}{lllll}
\hline $\begin{array}{l}\text { PVL by HIV-1 RNA } \\
\text { In copies/mL (log } \mathbf{1 0} \text { copies/mL) }\end{array}$ & Agreement & $\boldsymbol{\kappa}$ Value & $\begin{array}{l}\text { Number of samples } \\
\text { detected by Abbott } \mathbf{m 2 0 0 0 r t}\end{array}$ & $\begin{array}{l}\text { Percentage of Samples } \\
\text { detected by ExaVir Load V3 }\end{array}$ \\
\hline$\geq 200(2.3)$ & 89.1 & 0.46 & 580 & 90.7 \\
$\geq 400(2.6)$ & 88.1 & 0.57 & 550 & 93.5 \\
$\geq 1000(3.0)$ & 89.7 & 0.76 & 458 & 97.6 \\
$\geq 5000(3.7)$ & 94.4 & 0.89 & 344 & 99.7 \\
$\geq 10000(4.0)$ & 96.8 & 0.94 & 324 & 100 \\
PVL, plasma viral load; RT, reverse transcriptase. & & &
\end{tabular}



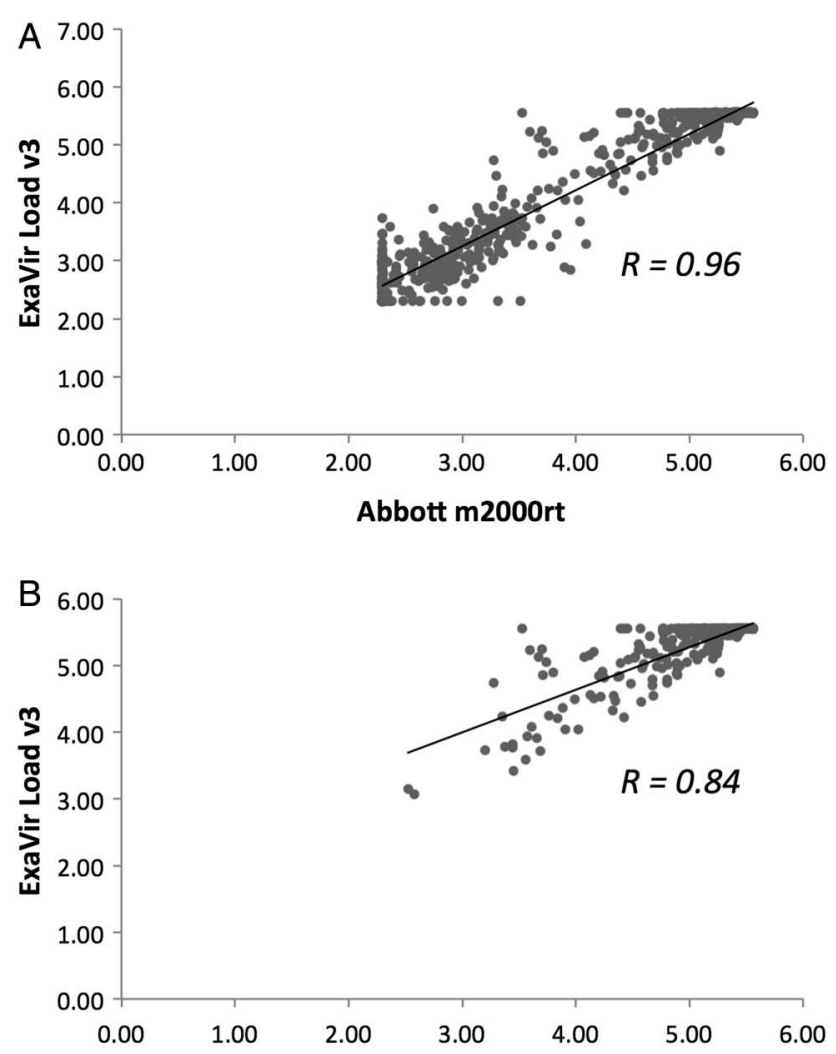

Abbott m2000rt

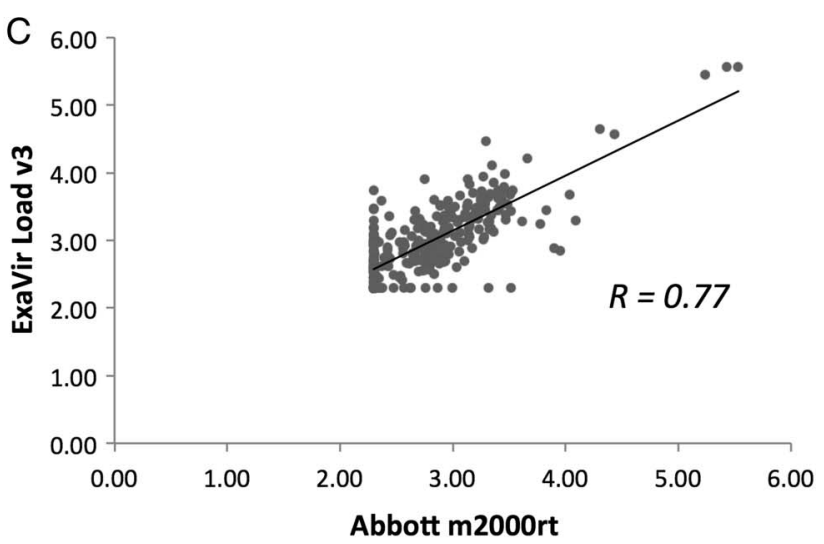

Figure 1 Correlation between the Abbott m2000rt and ExaVir Load V3 assays for (A) all 629 samples showing $r=0.96$ (B) 327 baseline (WKO0) samples showing $r=0.84$ and (C) 302 4-weeks post-ART (WK04) samples showing $r=0.77$. $\mathrm{ART}$, antiretroviral therapy.

$\left(<0.4 \log _{10}\right.$ copies $\left./ \mathrm{mL}\right)$ in mean $\log _{10}$ difference from the corresponding value among wild types. Although the samples with mutations are small, it indicates that the presence of NRTI and NNRTI DRMs did not negatively impact the test performance.

\section{Cost comparison of the assays}

The laboratory cost of viral load monitoring of HIV-infected patients analysed in our cohort by both Abbott m2000rt (HIV-1 RNA) and ExaVir Load V3 (HIV RT) is shown in table 3. The per test cost of the
A

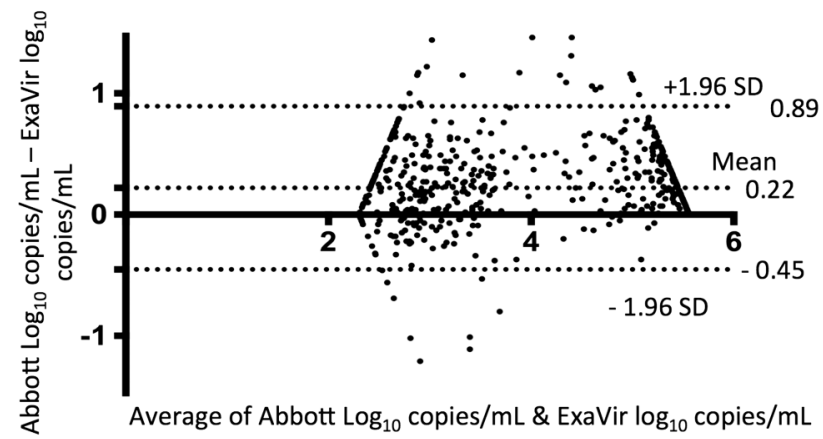

B

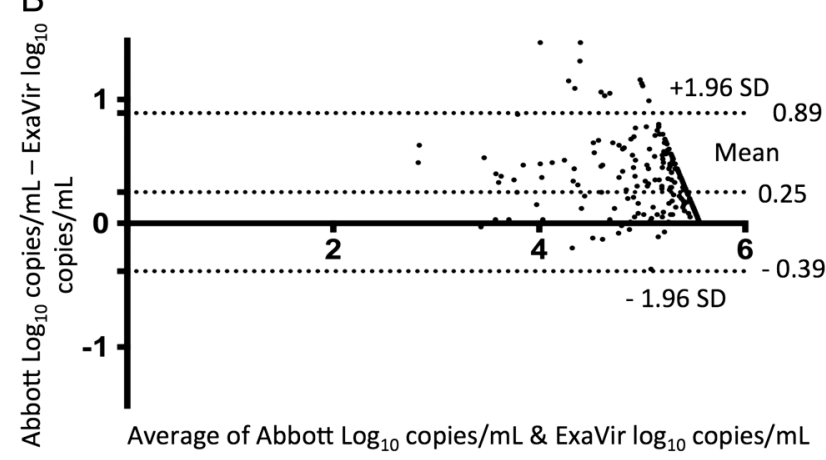

C

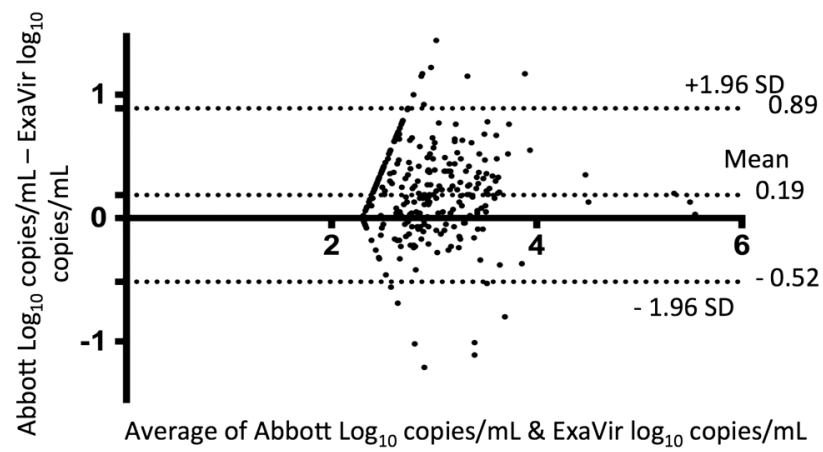

Figure 2 Bland-Altman plot with $95 \% \mathrm{Cl}$ of limits of agreement between HIV-1 viral loads measured with the Abbott Real-Time m2000rt assay and the ExaVir Load V3 assay for (A) all 629 samples showing a mean bias of 0.22 with $95 \%$ limits of agreement ranging from -0.45 to 0.89 (B) 327 baseline (WK00) samples showing a mean bias of 0.25 with $95 \%$ limits of agreement ranging from -0.39 to 0.89 (C) 3024 weeks post-ART (WK04) samples showing a mean bias of 0.19 with $95 \%$ limits of agreement ranging from -0.52 to 0.89. ART, antiretroviral therapy.

plasma viral load measured by Abbott m2000rt and ExaVir Load V3 was $\$ 36.4$ and $\$ 16.8$, respectively. Thus, by using ExaVir Load V3, \$19.6 per test can be saved. In a laboratory with a pre-existing basic set-up for ELISA-based assays, ExaVir Load V3 can be performed at $\$ 16.1$, saving $\$ 20.2$ per test. Most of the expense saved by using ExaVir Load V3 was due to (1) lower capital costs (instruments $\$ 37750$ against \$2000) (2) the lower cost of the assay reagents (\$15/test against $\$ 31 /$ test; table 3). 
Table 3 Cost comparison between the HIV RT assay and HIV-1 RNA assay for a laboratory doing 3000 tests/year

\begin{tabular}{lll}
\hline & $\begin{array}{l}\text { Abbott } \\
\text { m2000rt Cost } \\
\text { Cost items (\$) }\end{array}$ & $\begin{array}{l}\text { (\$) } \\
\text { ExaVir Load } \\
\text { V3 Cost (\$) }\end{array}$ \\
\hline $\begin{array}{l}\text { Annuitised costs of } \\
\text { capital instruments }\end{array}$ & 8719 & 462 \\
$\begin{array}{l}\text { Annuitised cost of } \\
\text { operator supplied } \\
\text { instruments }\end{array}$ & 293 & 1540 \\
$\begin{array}{l}\text { Annual maintenance cost } \\
\text { Costs of kits per year }\end{array}$ & 1126 & \\
$\begin{array}{l}\text { Consumables per year } \\
\text { Training time for lab staff } \\
\text { to run the test }\end{array}$ & 4616 & 666 \\
$\begin{array}{l}\text { Salary costs (3000 tests } \\
\text { per year) }\end{array}$ & 1200 & 45000 \\
$\begin{array}{l}\text { Total (\$) } \\
\text { Cost/test (\$) }\end{array}$ & 109634 & 50 \\
\hline $\begin{array}{l}\text { US } \$ 1=60 \text { INR. } \\
\text { RT, reverse transcriptase. }\end{array}$ & & 1000 \\
\hline
\end{tabular}

\section{DISCUSSION}

A good correlation between the HIV RT and HIV-1 RNA assays was observed in the current HIV-1C predominant setting in India. The agreement between the tests was not significantly affected by the NRTI/NNRTI-based antiretroviral regimen used. Earlier studies performed on panels of different subtypes and recombinants have suggested that the HIV RT assay detects all HIV-1 and HIV-2 subtypes with similar efficiency. ${ }^{14} 1530$ This assay, ExaVir Load V3, can therefore be an attractive option for viral load monitoring in Indian settings.

This study compared the ExaVir Load V3 assay with the Abbott m2000rt HIV-1 RNA assay and observed an excellent correlation $(r=0.96)$. An earlier study from London comparing the same tests observed a similar correlation $(\mathrm{r}=0.94) .{ }^{14}$ Strong correlations between the ExaVir Load V3 and Roche HIV-1 RNA-based assays have also been observed by two other studies, by Greengrass et $a l^{18}$ from Australia (Roche Cobas Amplicor; r=0.85) and Huang et $a l^{16}$ from China (Roche Cobas TaqMan 48; $\mathrm{r}=0.95$ ). Neither of these studies was performed in HIV-1C dominated settings. The HIV RT assay showed a good agreement with the HIV-1 RNA assay at the clinically important viral load threshold of 1000 copies/mL, which is used by the WHO to define viral failure to first-line therapy and is also most often used as the cut-off for drug resistance genotyping. ${ }^{31}$ The performance of the Exavir Load below 1000 copies/mL is moderate.

In general, we observed an underestimation of viral load of $0.22 \log _{10}$ RNA copies by the HIV RT assay, which is similar to what has been observed in other studies. ${ }^{141632}$ These two surrogate assays use very different methods for quantifying the plasma viral load. The HIV-1 RNA assays quantify the amount of viral RNA irrespective of RNA functionality, while the HIV RT assay quantifies the amount of active RT enzyme. The calibration constant used to translate RT activity into RNA copies was estimated from a study of an Australian cohort $^{18}$ and is not completely accurate for all combinations of HIV RNA assays and cohorts with varying subtype compositions. The variation observed is, however, well within the acceptable limit of $<0.5 \log _{10}$ copies.

NNRTI drugs bind to the RT enzyme, inhibit its activity and prevent viral replication. Several articles have discussed the possibility that enzymatically inactive RT drug complexes could result in under quantification of RT in relation to RNA. ${ }^{29} 3033$ These studies were, however, cross-sectional and never found any evidence for reduced RT activity during NNRTI therapy. In contrast to previous cohorts, the longitudinal sampling in our study provides optimal material for evaluation of the effects of NNRTI-based drug regimens. When comparing HIV viral load data from the same patient cohort before and after onset of ART, we found a mean $\log _{10}$ difference between ExaVir Load V3 and Abbott m2000rt of 0.25 for naïve patients and 0.19 for experienced patients (table 1). Thus, the difference between the tests did not increase after onset of therapy. This supports evidence that the current NNRTI containing therapy does not adversely influence the recovery of RT enzyme activity.

On a small number of samples, we assessed if the presence of drug-resistant mutations decreased the RT fitness so as to influence the performance of the HIV RT assay. We had six samples with single NRTI mutations and five samples with single NNRTI mutations and observed no evidence that their presence caused any significant difference in the association between RT enzyme activity and HIV-1 RNA load. These results were not unexpected and support evidence from previous studies by Napravnik et al and Rooijen et al indicating that the presence of NRTI or NNRTI mutations do not affect the relationship between RT enzyme activity and HIV-1 RNA load. ${ }^{34} 35$ Resistance to NRTIs is mediated by a primitive DNA editing function that is introduced into the HIV RT by certain mutations. An energy dependent base excision reaction removes the last base in the growing DNA chain. This requires an energy donator, usually ATP or GTP, and might decrease RT reaction velocity. This happens readily in vivo, but the reaction conditions in the current RT assay do not support this reaction. $^{36}$

To the best of our knowledge, this is the most thoroughly evaluated study of ExaVir Load V3 from India to date. Thus far, there have been three comparative studies from India that have been reported from the states of Andhra Pradesh (Anantpur), ${ }^{37}$ Tamil Nadu (Chennai) ${ }^{7}$ and New Delhi. ${ }^{32}$ Iqbal $e t a l^{7}$ from Chennai cross-sectionally evaluated the ExaVir Load assay V1 and Roche Amplicor Monitor assay. They found a good agreement between the two tests and a significant inverse correlation between ExaVir Load and CD4+ T-cell count. Alvarez-Uria et $a l^{37}$ from Anantpur 
compared the accuracy of ExaVir V3 with Roche Cobas TaqMan HIV-1 test and Roche Amplicor HIV-1 DNA assay for early infant diagnosis. ExaVir performed well showing $100 \%$ sensitivity and $99 \%$ specificity, but no quantitative correlations were evaluated. A more recent study by Kokkayil et $a \vec{l}^{2}$ compared ExaVir Load V3 with Roche Cobas TaqMan among 75 ART naïve patients and reported no statistically significant difference between the two assays.

There are a few drawbacks of the HIV RT assay. The long turnaround time of $48 \mathrm{~h}$ makes it appear labour intensive, though the actual hands-on time is approximately $5 \mathrm{~h}$. The prolonged incubation time is critical to achieve assay sensitivity. For standard performance, the assay requires $1 \mathrm{~mL}$ of plasma, which is high in comparison to the requirement for HIV-1 RNA assays, thus limiting its possible usefulness in paediatric populations. However, a recent study by Greengrass $e t a l^{19}$ observed that sample volumes down to $0.25 \mathrm{~mL}$ with $\mathrm{VL}>800$ copies/mL can be utilised for paediatric monitoring. The ExaVir Load assay does not provide a standard positive and negative control, thus requiring the lab to prepare its own controls, which may compromise the quality assurance of the assay. Additionally, we noted that the quality of the water used for washing is important as impurities and bacterial contaminants present in water may contain polymerases which can create background noise and increase the level of the lower detection limit.

In spite of these caveats, the HIV RT assay has advantages over the HIV-1 RNA assays in resource-limited settings because it is an ELISA-based assay and can be performed in any routine lab at a lower cost. The ExaVir Load assay requires a cheaper and maintenance free start-up kit as compared to real-time assays. We observed that performing the HIV RT assay routinely in our centre would save us $\$ 20.2$ per sample as compared to an HIV-1 RNA assay. A more basic laboratory, which requires installing basic ELISA equipment, would save $\$ 19.6$ per sample (table 3 ).

The use of CD4 cell count as a prognostic marker has been debated; it is argued that this count may not reflect the actual viral load status of the patient..$^{38}$ The cost associated with viral load monitoring using HIV-1 RNA assays, despite being lower than PCR assays, is a major limiting factor for its implementation. Currently, in India, viral load testing has been phased in to support patients failing firstline ART. In the year 2012, about 4157 viral load tests were performed under the National AIDS Control Organisation (NACO). ${ }^{39}$ Considering that $\$ 19.6$ could have been saved per sample by performing an HIV RT assay, the cost saving for these 4157 viral load tests could have amounted to $\$$ 81477 if an HIV RT assay had been used.

In our cost-comparison analysis, we have used a provider perspective (lab service). We acknowledge that this is a narrower perspective than a societal one, which would include patient costs, opportunity costs among other costs. However, the purpose of our analysis was to provide information to laboratories in resource constrained settings, often faced with decisions in the face of tight budgets, and thus a societal perspective was not considered necessary. A laboratory manager faced with a limited budget would concentrate entirely on costs that have an immediate impact on her/his own budget; this is the perspective adopted in this study.

NACO is now considering taking up the monitoring approach recommended by the WHO to diagnose and confirm ART failure. Considering that there are currently 604987 HIV-1-infected individuals receiving firstline ART at 380 centres spread across the country, the cost reduction of utilising HIV RT compared to HIV RNA plasma load can be substantial. ${ }^{40}$

Scaling up ART requires the critical support of HIV-1 viral load monitoring. Evidence from the comparative performance of the HIV RT assay with HIV-1 RNA assays from ours and other studies from India indicates that the ExaVir Load assay could serve as an affordable alternative to monitor patients on ART.

\section{Author affiliations}

${ }^{1}$ Division of Clinical Virology, Department of Microbiology, St. John's Medical College, Bangalore, India

${ }^{2}$ Division of Clinical Microbiology, Department of Laboratory Medicine, Karolinska Institutet, Stockholm, Sweden

${ }^{3}$ Department for International Health, University of Tampere School of Medicine, Tampere, Finland

${ }^{4}$ Department of Public Health Sciences, Karolinska Institute, Stockholm, Sweden

${ }^{5}$ Cavidi AB, Uppsala, Sweden

${ }^{6}$ Department of Pediatrics, St John's Medical College Hospital, Bangalore, India

Acknowledgements The authors would like to thank the HIVIND study team for their outstanding efforts in recruiting and following the study participants and collection of samples. They would also like to thank Pravat Nalini Sahoo and Shwetha D Rao, St. John's Research Institute, for performing laboratory experiments pertaining to HIV-1 drug resistance and HIV-1 RNA load. They are very much thankful to Staffan Sjödahl, Cavidi AB for his technical help and support with the ExaVir Load V3 assay. Ujjwal Neogi acknowledges the support received from Karolinska Institutet Research Foundation Grants (2014fobi41250). The authors also acknowledge the staff at the ART Centre, St. John's Medical College Hospital and KR Hospital, Mysore for their excellent teamwork and patient care and NACO and Karnataka State AIDS Prevention Society (KSAPS) for their support. Most importantly, they are ever thankful to the patients for their participation in the study.

Contributors UN, ADC, CK, PA and AS conceived the study. SG, UN, HS, $A D C, C K$ and $A S$ designed the experiments. $S G$ and RP performed the experiments. PA was responsible for external lab monitoring and interim quality assessment. SG, UN, ADC, CK and AS analysed the data. CK and AS contributed reagents/materials/analysis tools. SG, RP, UN, HS, PA, ADC, CK and AS contributed to the writing of the manuscript.

Funding The study was financially supported by a grant under the European Union Framework Programme 7 (project no: 222946).

Competing interests $\mathrm{CK}$ is an employee of Cavidi $\mathrm{AB}$, Uppsala, Sweden. All the other authors have declared that no competing interests exist.

\section{Patient consent Obtained.}

Ethics approval Ethical approvals for the conduct of the trial were obtained from the Institutional Ethical Review Board of St John's Medical College Hospital, Bangalore (IERB 1/369/08-92/2008) and Krishna Rajendra Hospital, Mysore (NO/PS/173/2010). All patients participating in the HIVIND study have given their written consent. 
Provenance and peer review Not commissioned; externally peer reviewed.

Data sharing statement No additional data are available.

Open Access This is an Open Access article distributed in accordance with the Creative Commons Attribution Non Commercial (CC BY-NC 4.0) license, which permits others to distribute, remix, adapt, build upon this work noncommercially, and license their derivative works on different terms, provided the original work is properly cited and the use is non-commercial. See: http:// creativecommons.org/licenses/by-nc/4.0/

\section{REFERENCES}

1. Neogi $U$, Heylen $E$, Shet A, et al. Long-term efficacy of first line antiretroviral therapy in Indian HIV-1 infected patients: a longitudinal cohort study. PLOS ONE 2013;8:e55421.

2. Antiretroviral Therapy Cohort Collaboration. Life expectancy of individuals on combination antiretroviral therapy in high-income countries: a collaborative analysis of 14 cohort studies. Lancet 2008;372:293-9.

3. Bryant L, Smith N, Keiser P. A model for reduced HIV-1 viral load monitoring in resource-limited settings. J Int Assoc Provid AIDS Care 2013;12:67-71

4. Crowe S, Turnbull S, Oelrichs R, et al. Monitoring of human immunodeficiency virus infection in resource-constrained countries. Clin Infect Dis 2003;37(Suppl 1):S25-35.

5. Rawizza HE, Chaplin B, Meloni ST, et al. Immunologic criteria are poor predictors of virologic outcome: implications for HIV treatment monitoring in resource-limited settings. Clin Infect Dis 2011;53:1283-90.

6. Wilson D, Keiluhu AK, Kogrum S, et al. HIV-1 viral load monitoring: an opportunity to reinforce treatment adherence in a resource-limited setting in Thailand. Trans R Soc Trop Med Hyg 2009;103:601-6.

7. Iqbal HS, Balakrishnan P, Cecelia AJ, et al. Use of an HIV-1 reverse-transcriptase enzyme-activity assay to measure HIV-1 viral load as a potential alternative to nucleic acid-based assay for monitoring antiretroviral therapy in resource-limited settings. $J$ Med Microbiol 2007; 56(Pt 12):1611-14.

8. Stewart P, Cachafeiro A, Napravnik S, et al. Performance characteristics of the Cavidi ExaVir viral load assay and the ultra-sensitive P24 assay relative to the Roche Monitor HIV-1 RNA assay. J Clin Virol 2010;49:198-204.

9. Stevens WS, Scott LE, Crowe SM. Quantifying HIV for monitoring antiretroviral therapy in resource-poor settings. J Infect Dis 2010;201 (Suppl 1):S16-26.

10. Sivapalasingam S, Wangechi B, Marshed F, et al. Monitoring virologic responses to antiretroviral therapy in HIV-infected adults in Kenya: evaluation of a low-cost viral load assay. PLOS ONE 2009;4: e6828.

11. Seyoum E, Wolday D, Girma M, et al. Reverse transcriptase activity for quantitation of HIV-1 subtype $C$ in plasma: relation to RNA copy number and CD4 T-cell count. J Med Virol 2006;78:161-8.

12. Malmsten A, Shao XW, Sjodahl S, et al. Improved HIV-1 viral load determination based on reverse transcriptase activity recovered from human plasma. J Med Virol 2005;76:291-6.

13. Lombart JP, Vray M, Kafando A, et al. Plasma virion reverse transcriptase activity and heat dissociation-boosted p24 assay for HIV load in Burkina Faso, West Africa. AIDS 2005;19:1273-7.

14. Labbett W, Garcia-Diaz A, Fox Z, et al. Comparative evaluation of the ExaVir Load version 3 reverse transcriptase assay for measurement of human immunodeficiency virus type 1 plasma load $J$ Clin Microbiol 2009;47:3266-70.

15. Jennings $\mathrm{C}$, Fiscus SA, Crowe SM, et al. Comparison of two human immunodeficiency virus (HIV) RNA surrogate assays to the standard HIV RNA assay. J Clin Microbiol 2005;43:5950-6.

16. Huang D, Zhuang Y, Zhai S, et al. HIV reverse transcriptase activity assay: a feasible surrogate for HIV viral load measurement in China. Diagn Microbiol Infect Dis 2010;68:208-13.

17. Greengrass VL, Turnbull SP, Hocking J, et al. Evaluation of a low cost reverse transcriptase assay for plasma HIV-1 viral load monitoring. Curr HIV Res 2005;3:183-90.

18. Greengrass VL, Plate MM, Steele PM, et al. Evaluation of the Cavid ExaVir Load assay (version 3) for plasma human immunodeficiency virus type 1 load monitoring. J Clin Microbiol 2009;47:3011-13.

19. Greengrass V, Lohman B, Morris L, et al. Assessment of the low-cost Cavidi ExaVir Load assay for monitoring HIV viral load in pediatric and adult patients. $J$ Acquir Immune Defic Syndr 2009:52:387-90.

20. Shao Y, Williamson C. The HIV-1 epidemic: low- to middle-income countries. Cold Spring Harb Perspect Med 2012;2:a007187.

21. Mine M, Bedi K, Maruta T, et al. Quantitation of human immunodeficiency virus type 1 viral load in plasma using reverse transcriptase activity assay at a district hospital laboratory in Botswana: a decentralization pilot study. J Virol Methods 2009;159:93-7.

22. Stevens G, Rekhviashvili N, Scott LE, et al. Evaluation of two commercially available, inexpensive alternative assays used for assessing viral load in a cohort of human immunodeficiency virus type 1 subtype C-infected patients from South Africa. J Clin Microbiol 2005;43:857-61.

23. Shet A, Costa AD, Kumarasamy N, et al. Effect of mobile telephone reminders on treatment outcome in HIV: evidence from a randomised controlled trial in India. BMJ 2014;347:g5978.

24. NACO, Department of AIDS Control, Ministry of Health and Family Welfare, Annual Report 2012-13. http://www.nacoonline.org/upload/ Publication/AnnualReport/Annualreport2012-13_English.pdf (accessed on $8 \mathrm{Jul}$ 2013).

25. Neogi U, Prarthana BS, Gupta S, et al. Naturally occurring polymorphisms and primary drug resistance profile among antiretroviral-naive individuals in Bangalore, India. AIDS Res Hum Retroviruses 2010;26:1097-101.

26. Gupta S, Neogi U, Srinivasa H, et al. HIV-1 co-receptor tropism in India: increasing proportion of X4-tropism in subtype C strains over two decades. J Acquir Immune Defic Syndr 2014;65:397-404.

27. Neogi U, Bontell I, Shet A, et al. Molecular epidemiology of HIV-1 subtypes in India: origin and evolutionary history of the predominant subtype C. PLOS ONE 2012;7:e39819.

28. Neogi U, Gupta S, Palchaudhuri R, et al. Limited evolution but increasing trends of primary non-nucleoside reverse transcriptase inhibitor resistance mutations in therapy-naive HIV-1-infected individuals in India. Antivir Ther (Lond) 2014;19:813-18.

29. Bennett DE, Camacho RJ, Otelea D, et al. Drug resistance mutations for surveillance of transmitted HIV-1 drug-resistance: 2009 update. PLOS ONE 2009;4:e4724.

30. Steegen K, Luchters S, De Cabooter N, et al. Evaluation of two commercially available alternatives for HIV-1 viral load testing in resource-limited settings. J Virol Methods 2007:146:178-87.

31. World Health Organization. Consolidated guidelines on the use of antiretroviral drugs for treating and preventing HIV infection. Recommendations for a public health approach. Geneva, Switzerland: World Health Organization, 2013.

32. Kokkayil P, Kurapati S, Negi N, et al. Comparative evaluation of a reverse transcriptase based assay for HIV-1 viral load quantitation in resource limited settings. J Virol Methods 2014;203:1-4.

33. Malmsten A, Shao XW, Aperia K, et al. HIV-1 viral load determination based on reverse transcriptase activity recovered from human plasma. J Med Virol 2003;71:347-59.

34. van Rooijen LB, Greengrass V, Morris LM, et al. Effect of reverse transcriptase inhibitors and mutations on the low-cost Cavidi reverse transcriptase viral load assay. J Acquir Immune Defic Syndr 2009;52:527-9.

35. Napravnik S, Cachafeiro A, Stewart P, et al. HIV-1 viral load and phenotypic antiretroviral drug resistance assays based on reverse transcriptase activity in comparison to amplification based HIV-1 RNA and genotypic assays. J Clin Virol 2010;47:18-22.

36. Shao XW, Malmsten A, Lennerstrand J, et al. Use of HIV-1 reverse transcriptase recovered from human plasma for phenotypic drug susceptibility testing. AIDS 2003:17:1463-71.

37. Alvarez-Uria G, Azcona JM, Reddy S, et al. Point of care testing of HIV in children younger than 18 months with three different HIV virological assays. Experience from a district hospital in a resource-limited setting. Microbiology Research 2012;3:e14.

38. Sax PE. Editorial commentary: can we break the habit of routine CD4 monitoring in HIV care? Clin Infect Dis 2013;56:1344-6.

39. Ataher Q, Portsmouth S, Napolitano LA, et al. The epidemiology and clinical correlates of HIV-1 co-receptor tropism in non-subtype B infections from India, Uganda and South Africa. J Int AIDS Soc 2012;15:2.

40. Vitoria M, Vella S, Ford N. Scaling up antiretroviral therapy in resource-limited settings: adapting guidance to meet the challenges. Curr Opin HIV AIDS 2013;8:12-18. 